\title{
Strategic Asset Allocation Of Credit Guarantors
}

\author{
Dong Woo Rhee, Credit Guarantee \& Investment Facility, Philippines \\ Hyoung-Goo Kang, Hanyang University, South Korea \\ Soo-Hyun Kim, Soongsil University, South Korea
}

\begin{abstract}
How to manage the portfolio of credit guarantors is important in practice and public policy, but has not been investigated well in the prior literature. We empirically compare four different approaches in managing credit guarantor portfolios. The four approaches are equal weighted, minimum variance, mean variance optimization and equal risk contribution methods. In terms of risk return ratio, the mean variance optimization model performs best in out-of-sample test. This result contrasts with previous findings against mean variance optimization. Our results are robust. The results do not change as the characteristics of guarantee portfolio vary.
\end{abstract}

Keywords: Strategic Asset Allocation; Guarantee Portfolio; Mean-Variance Optimization; Minimum Variance Portfolio; Equal Risk Portfolio

\section{INTRODUCTION}

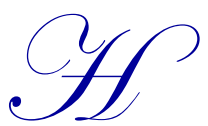

ow to undertake strategic asset allocation for a credit guarantor's capital is important in practice and public policy. This problem involves several distinct characteristics. First, a board or management determines the allocation to a guarantee portfolio. Strategic asset allocation does not produce how much to invest in a guarantee portfolio, but only determines how to allocate a given amount across each asset. This situation resembles Schweizer (1992) on how to solve a hedging problem using a mean variance framework for already given contingent claims.

Second, a guarantee does not require capital injection. The allocation to a guarantee portfolio does not affect the total sum of allocations to other assets. However, it does affect the relative allocation across each asset because the characteristics of a guarantee portfolio correlate with the risks of each asset.

Third, a credit guarantor generally invests only in bonds and thus focuses on micro allocation across bonds. For example, the guarantor could concern the allocation between treasuries and corporate bonds. Walder (2002) examines the optimal weights for a portfolio composed of default free bonds and defaultable bonds. Duffee (1998) and Dullmann et al (2000) find significant negative correlations between credit spreads and treasury yields in both US and German markets. Hence, they recommend treasuries to play a significant role as credit guarantors; treasuries can reduce risks in a bond portfolio as credit spreads reflect their fundamentals.

The mean variance model (Markowitz, 1952, 1956) is a traditional asset allocation framework. Widely implemented by many practitioners thanks to its neat and simple logic, it is, however, subject to drawbacks. They are overly sensitive to input parameters, especially expected return. As Merton (1980) indicates, small changes in expected returns can change portfolio weights dramatically. Alternative models have been suggested to overcome these drawbacks. Michaud (1989) proposes portfolio resampling while Tutuncu and Koenig (2004) suggest robust asset allocation. Jorion (1986) notices the problems of shrinkage estimators incorporated in those approaches. Scherer (2007) points out that alternative models are no better than traditional models due to their own weaknesses including computational burden.

After the global financial crisis in 2008, both practitioners and academic researchers further investigated minimum variance, equal weight and equal risk portfolios. These methods do not require estimating expected returns 
and often outperform market portfolios in absolute return basis (Clarke, De Silva, and Thorley, 2006; Behr, Guttler, and Miebs, 2008; Martellini, 2008; Choueifaty and Coignard, 2008). However, there are still issues. First, the minimum variance portfolio is simply a point on the mean variance efficient frontier. Therefore, although it is free from the estimation of expected returns, it suffers portfolio concentration, i.e. corner solutions.

Second, the equal weight portfolio is an easy solution assigning equal weights to each asset. Equal weighting is popular among practitioners although it may look too simple (Bernartzi and Thaler, 2001; Windcliff and Boyle, 2004). Equal weighting possibly can generate efficient out-of-sample performances (Demiguel, Garlappi and Uppal, 2009).

Third, the equal risk portfolio equalizes risk contribution of each asset to the whole portfolio. This exhibits volatility larger than that of the minimum variance portfolio but smaller than that of the equal weighted portfolio. See empirical works by Neurich (2008) and Qian (2005) and theoretical ones by Maillard, Roncalli, and Teiletche (2010). Allen (2010), Foresti and Rush (2010), Fernholtz et al. (1998), Booth and Fama (1992) show that risk diversification can enhance returns. Qian (2006) argues that risk contributions are of financial significance and interpretation because they signal expected contribution of each asset to the losses. According to Roncalli (2013), many institutional investors use the equal risk approach for their long-term investment policies. However, Inker (2010) criticizes that equal-risk weighting results in a sub-optimal portfolio. Levell (2010) and Foresti and Rush (2010) argue that equal-risk weighting amplifies the tail risk.

This paper focuses on portfolio problems of a credit guarantor and produces unique contributions to academic researchers and practical managers. First, we conduct a horse race to find out the best asset allocation method for a credit guarantor. We compare mean variance optimization, minimum variance, equal weight, and equal risk in out of sample. As a credit guarantor generally invests only in bonds, we highlight sector or maturity allocations among bonds. Second, we show how optimal allocation results change as the average credit rating of underlying guarantees, the average maturity of underlying guarantees and the leverage of guarantee portfolio change. We also demonstrate which asset allocation model provides the best out-of-sample performance as the characteristic of guarantee portfolio vary. We offer economic interpretations on our results.

Our findings extend existing literature. First, mean variance optimization shows the best performance in terms of risk return ratio among the four asset allocation models examined. This result contrasts with Chaves, Hsu, $\mathrm{Li}$ and Shakernia (2010) in that equal risk models outperform mean variance optimization or minimum variance models. Second, mean variance optimization always performs best regardless of guarantee portfolio's characteristics. Third, the riskier the guarantee portfolio becomes, the more allocation to treasury and long-term bonds the mean variance optimization recommends. Equal risk model generates similar recommendations.

\section{MODELS}

A credit guarantor should decide how much money to allocate to each investment portfolio with the size of the guarantee portfolio given. A guarantee is a financial instrument and does not require capital injection. Thus, a guarantee portfolio does not consume any capital regardless of its size. However, it affects the portfolio allocation problem of a credit guarantor who maximizes risk return ratio of a firm exposed to both investment portfolio and guarantee portfolio.

Let us assume that there are four investment portfolios in which a credit guarantor can invest. The allocation weights are $w_{1}, w_{2}, w_{3}$, and $w_{4}$. The returns are $R_{1}, R_{2}, R_{3}$, and $R_{4}$, respectively. There is a guarantee portfolio, $G$. Its return is $R_{\mathrm{G}}$. $L$ denotes the leverage of the guarantee portfolio meaning $L$ times as big as the size of the credit guarantor capital. Then, the total return, $R_{\mathrm{p}}$, for the credit guarantor is:

$$
\begin{gathered}
R_{p}=w_{1} R_{1}+w_{2} R_{2}+w_{3} R_{3}+w_{4} R_{4}+L R_{G} \\
\text { and } \sum_{i=1}^{4} w_{i}=1 .
\end{gathered}
$$


This equation can be expressed as follows.

$$
R_{p}=w_{1}\left(R_{1}+L R_{G}\right)+w_{2}\left(R_{2}+L R_{G}\right)+w_{3}\left(R_{3}+L R_{G}\right)+w_{4}\left(R_{4}+L R_{G}\right) .
$$

\section{Mean Variance Optimization}

In mean variance optimization, the optimal solutions maximize the following objective function:

$$
\max =\frac{E\left(R_{p}\right)}{\sigma_{p}} .
$$

Instead of excess return over risk free rate, we use $E\left(R_{\mathrm{p}}\right)$ for the numerator because risk-free assets cannot be assumed when a guarantee portfolio exists. The constraints of this objective function are:

$$
\begin{gathered}
\sum_{i=1}^{N} w_{i}=1, \text { all } w_{i} \geq 0 \\
\text { Where, } E\left(R_{p}\right)=\sum_{i=1}^{N} w_{i} E\left(R_{i}^{\prime}\right) \quad \sigma_{p}^{2}=\sum_{i=1}^{N} \sum_{j=1}^{N} w_{i} w_{j} \sigma_{i j} .
\end{gathered}
$$

$R_{\mathrm{i}}^{\prime}$ is $R_{\mathrm{i}}+L R_{\mathrm{G}} . \sigma_{\mathrm{ij}}$ is the covariance between $R_{\mathrm{i}}^{\prime}$ and $R_{\mathrm{j}}^{\prime} . R_{\mathrm{p}}$ is the credit guarantor's total return reflecting both investment portfolio returns and the guarantee portfolio return.

\section{Minimum Variance}

The optimal weights from mean variance optimization are unstable and largely affected by the expected returns hard to estimate correctly. A minimum variance portfolio is an interesting alternative independent of estimated expected returns. The same as mean variance optimization, each asset is defined as an investment portfolio plus the guarantee portfolio with notional amount, $L$. The optimal weights from minimum variance solve:

$$
\begin{gathered}
\min =\sigma_{p} \\
\text { where, } \sigma_{p}^{2}=\sum_{i=1}^{N} \sum_{j=1}^{N} w_{i} w_{j} \sigma_{i j}, \\
\sum_{i=1}^{N} w_{i}=1, \text { all } w_{i} \geq 0
\end{gathered}
$$

\section{Equal Risk}

A minimum variance portfolio is robust, not incorporating the expected returns. However, it generally suffers portfolio concentration. Equal risk approach is similar to minimum variance approach uninfluenced by expected returns. In addition, it tends to produce well distributed and reasonable allocation.

In equal risk approach, different assets contribute equally to portfolio risk. The risk contribution is computed as (the allocation in asset $i$ ) $\mathrm{x}$ (its marginal risk contribution). The marginal risk contribution is the change in the total risk of a portfolio induced by an infinitesimal increase in holdings of asset $i$. Thus, the marginal risk contribution, $\partial \sigma(w)$, is defined as follows.

$$
\partial_{w_{i}} \sigma(w)=\frac{\partial \sigma(w)}{\partial w_{i}}=\frac{w_{i} \sigma_{i}^{2}+\sum_{j \neq i} w_{j} \sigma_{i j}}{\sigma(w)} .
$$


The risk contribution of the $i^{\prime}$ th asset is:

$$
\sigma_{i}(w)=w_{i} \times \partial_{w_{i}} \sigma(w) .
$$

The weights from an equal risk portfolio are determined at the point where the risk contribution of each asset is identical $\left(\sigma_{\mathrm{i}}(w)=\sigma_{\mathrm{j}}(w)\right.$ for $i$ and $\left.j\right)$. Due to the endogeneity of equations, finding solutions requires a numerical approach as follows.

$$
\begin{aligned}
& w^{*}=\arg \min f(w) \\
& \text { where, } f(w)=\sum_{i=1}^{n} \sum_{j=1}^{n}\left(\sigma_{i}(w)-\sigma_{j}(w)\right)^{2}
\end{aligned}
$$

\section{DATA}

In this study, a hypothetical guarantor undertakes investments in corporate and treasury bonds denominated in US dollars for her capital. She uses the capital as the resource to pay out to investors upon default for the loss at the bonds she guarantees. Hence, her capital generally comprises only high-grade bonds. Thus, we select the following four fixed income indices as the eligible investment portfolios for the credit guarantor: US treasury 1-5Y (UST 1-5Y) index, US treasury 5-10Y (UST 5-10Y) index, AA rated bond 1-5Y (AA 1-5Y) index and AA rated bond 5-10Y (AA 5-10Y) index.

These indices are all from Barclays. The AA rated bond index includes the bonds with average credit rating AA, issued in US dollars. It includes corporate bonds and government or government related bonds. We choose these indices with two different maturities and two different sectors in order to analyze the influence of the characteristics of guarantee portfolio on asset allocation solutions. This also highlights the optimal allocations between treasury bonds and corporate bonds or between short-term bonds and long-term bonds. More maturities and sectors may give more specific allocation results. However, high correlation between similar indices reduces additional diversification benefits. Some indices do not have data with the sufficient length required in this study.

A guarantee portfolio is fundamentally the combination of long corporate bonds and a short treasury bonds portfolio. We analyze three guarantee portfolios: high-grade short-term guarantee portfolio, high-yield short-term guarantee portfolio, and high-grade long-term guarantee portfolio.

The high-grade short-term guarantee portfolio longs high-grade 1-5Y corporate bond index and shorts US treasury 1-5Y index. The high-yield short-term guarantee portfolio longs high-yield 1-5Y corporate bond index and shorts US treasury $1-5 \mathrm{Y}$ index. The high-grade long-term guarantee portfolio longs the average of high-grade $1-5 \mathrm{Y}$ corporate bond index and high-grade 5-10Y corporate bond index while shorting the average of US treasury 1-5Y index and US treasury 5-10Y index. All indices are from Barclays.

We use monthly return data of bond indices and guarantee portfolios. For the portfolio allocation weights of a particular year, we use the parameters estimated with prior three years' monthly data. The allocation weights from 1995 to 2013 are estimated from the data from January 1992 to December 2012.

On the other hand, a guarantee portfolio return in a year is projected as $50 \% \mathrm{x}$ average credit spread for the previous years - the real default rate in the year $\mathrm{x}$ loss given default. The real default rate is collected from S\&P. For high-grade short-term guarantee portfolio, the average credit spread is the average yield difference between highgrade $1-5 \mathrm{Y}$ corporate bond index and US treasury $1-5 \mathrm{Y}$ index during past five years just before the particular year. In practice, a credit guarantor cannot receive full credit spread as a guarantee fee. Hence, we assume a guarantor will receive $50 \%$ of credit spreads.

S\&P provides three kinds of annual default rate: total default rate, investment-grade default rate, and speculative-grade default rate. Using invest-grade default rate underestimates defaults by ignoring those downgraded from investment to speculative grades. Using speculative-grade default rate overestimates the default rates of high- 
grade guarantee portfolio. Hence, we use the total default rate throughout all credit ratings for the default rates of high-grade guarantee portfolio.

Likewise, the average credit spread for high-yield short-term guarantee portfolio is the average yield difference between high-yield 1-5Y corporate bond index and US treasury 1-5Y index for the past five years just before a year. We use the speculative grade default rate for the default rates of high-yield guarantee portfolio. The return of high-grade long-term guarantee portfolio is constructed similar to that of high-grade short-term guarantee portfolio, except that the former uses the average credit spread calculated with past 10-year while the latter uses 5year data. If the guarantee portfolio is leveraged (e.g. $200 \%$ of the guarantor's total capital), the return of the guarantee portfolio is also multiplied according (e.g. two times).

In sum, out of sample performance per year is an investment portfolio return plus a guarantee portfolio return. The former uses the returns of bond indices and their weights. The latter additionally uses credit spread and default rate.

For the expected returns of the bond indices, we use the weighted average yield to maturity (hereafter 'yield') at the last observation point in three years for estimating parameters. Therefore, we do not use historical returns. The lower the current yield, the more likely the past returns are higher, but the less likely the future returns would occur. Thus, current yield is a better proxy for expected return than historical return. The expected return of the guarantee portfolio uses $50 \%$ percent of the average credit spread as guarantee income. See the descriptive statistics at Table 1.

Panel A In Table 1 shows the descriptive statistics for 252 monthly returns of the followings: US treasury 1-5Y index (UST 1-5Y Index), US treasury 5-10Y index (UST 5-10Y Index), AA rated bond 1-5Y index (AA 1-5Y Index), AA rated bond 5-10Y index (AA 5-10Y Index), Long High-Grade corporate bond 1-5Y index (HG 1-5Y Index) and short UST 1-5Y index, Long High-Yield corporate bond 1-5Y index (HY 1-5Y Index) and short UST 1$5 \mathrm{Y}$ index, and Long High-Grade corporate bond 1-10Y index (HG 1-10Y Index) and short UST 1-10Y index. The data spans from January 1992 to December 2012. In Panel B, the descriptive statistics for 19 annual returns of the following are presented: UST 1-5Y Index, UST 5-10Y Index, AA 1-5Y Index, AA 5-10Y Index, 50\% times the average of past five years' yield differences between the high-grade corporate bond 1-5Y index (HG ST Spread) and the UST $1-5 \mathrm{Y}$ index minus default rate (DR) times loss given default (LGD), $50 \%$ times the average of past ten years' yield differences between the high-grade corporate bond 1-10Y index (HG LT Spread) and the UST 1-10Y index minus DR times LGD, 50\% times the average of past five years' yield differences between high-yield corporate bond 1-5Y index (HY ST Spread) and UST 1-5Y index minus speculative grade default rate (SDR) times LGD. The data spans from 1995 through 2013. 1-10Y index is the average of 1-5Y index and 5-10Y index.

Table 1. Descriptive Statistics of Bond Indices and Projected Guarantee Portfolios Panel A: Statistics of Monthly returns from January 1992 through December 2012

\begin{tabular}{lccccc}
\hline \multicolumn{1}{c}{ Indices } & Average & Volatility & Max & Min & Skewness \\
\hline UST 1-5Y Index & $0.41 \%$ & $0.67 \%$ & $2.30 \%$ & $-1.65 \%$ & -0.02 \\
UST 5-10Y Index & $0.57 \%$ & $1.65 \%$ & $7.02 \%$ & $-4.95 \%$ & -0.06 \\
AA 1-5Y Index & $0.43 \%$ & $0.65 \%$ & $2.32 \%$ & $-1.62 \%$ & -0.09 \\
AA 5-10Y Index & $0.59 \%$ & $1.51 \%$ & $5.79 \%$ & $-5.05 \%$ & -0.21 \\
Long HG 1-5Y Index Short UST 1-5Y Index & $0.08 \%$ & $0.63 \%$ & $3.00 \%$ & $-5.51 \%$ & -2.64 \\
Long HG 1-10Y Index Short UST 1-10Y Index & $0.06 \%$ & $0.92 \%$ & $4.13 \%$ & $-6.60 \%$ & -1.35 \\
Long HY 1-5Y Index Short UST 1-5Y Index & $0.27 \%$ & $2.11 \%$ & $8.82 \%$ & $-11.27 \%$ & -1.34 \\
\hline
\end{tabular}

Panel B: Statistics of Annual returns from 1995 through 2013

\begin{tabular}{|c|c|c|c|c|c|}
\hline Indices & Average & Volatility & Max & Min & Skewness \\
\hline UST 1-5Y Index & $4.73 \%$ & $3.54 \%$ & $12.03 \%$ & $-0.14 \%$ & 0.33 \\
\hline UST 5-10Y Index & $6.56 \%$ & $6.97 \%$ & $19.48 \%$ & $-4.68 \%$ & -0.06 \\
\hline AA $1-5$ Y Index & $5.02 \%$ & $3.07 \%$ & $12.20 \%$ & $0.29 \%$ & 0.58 \\
\hline AA 5-10Y Index & $6.89 \%$ & $5.31 \%$ & $19.67 \%$ & $-3.31 \%$ & 0.10 \\
\hline $50 \% *$ HG ST Spread - DR * LGD & $-0.20 \%$ & $0.68 \%$ & $0.55 \%$ & $-1.48 \%$ & -0.78 \\
\hline $50 \% *$ HG LT Spread - DR $*$ LGD & $-0.22 \%$ & $0.63 \%$ & $0.44 \%$ & $-1.45 \%$ & -0.91 \\
\hline $50 \% *$ HY ST Spread - SDR $*$ LGD & $0.51 \%$ & $1.80 \%$ & $2.61 \%$ & $-2.83 \%$ & -0.66 \\
\hline
\end{tabular}




\section{EMPIRICAL RESULTS}

Table 2 shows the out of sample performance of four asset allocation methods when the size of high-grade short-term guarantee portfolio is the same as that of the investment portfolio ( $100 \%$ leverage). Mean variance optimization beats the other methods in terms of risk return ratio. Its average allocation to US treasuries is about $19 \%$, the smallest among four models. The allocation to short maturity indices is $88 \%$ implying that short-term corporate bonds are key assets.

On the other hand, the other three models allocate less weight to the AA 1-5Y index. The volatility of the AA 1-5Y index is lower than that of US treasury (UST) 1-5Y index (panel A, Table 1). The volatility of the combination of the US treasury (UST) $1-5 \mathrm{Y}$ index and high-grade short-term guarantee portfolio is lower than that of both the AA 1-5Y index and high-grade short-term guarantee portfolio (Table 3). Thus, a guarantee portfolio is more positively correlated with the AA 1-5Y index than the US treasury 1-5Y index. This is in line with common sense. A guarantee usually has similar credit of the AA 1-5Y index. The UST 1-5Y index shows the lowest volatility after the guarantee portfolio is included. Hence, minimum variance and equal risk models allocate most weight to the UST $1-5 \mathrm{Y}$ index since they do neither consider returns nor allow the assets having higher volatilities to be allocated more despite high correlations between bond indices.

Table 2. Out of Sample Performance: 100\% Leverage on High-grade Short-term Guarantee Portfolio Out of sample performances are the annual performances from 1995 to 2013 of four asset allocation models. Annual return is the sum of the annual investment portfolio return and the annual guarantee portfolio return projected with annual default rate and the average high-grade short-term credit spread from past five years. The parameters for models are estimated with previous threeyear monthly data ending December just before a target year. Leverage is $100 \%$.

\begin{tabular}{lccrc}
\hline & Equal Weight & $\begin{array}{c}\text { Mean-Variance } \\
\text { Optimization }\end{array}$ & $\begin{array}{c}\text { Minimum } \\
\text { Variance }\end{array}$ & Equal Risk \\
\hline Average Return & $5.61 \%$ & $5.36 \%$ & $4.39 \%$ & $5.29 \%$ \\
S.D. of Returns & $4.28 \%$ & $3.04 \%$ & $3.30 \%$ & $3.83 \%$ \\
Risk Return Ratio & 1.31 & 1.76 & 1.33 & 1.38 \\
Worst Year's Return & $-1.49 \%$ & $-0.19 \%$ & $-1.22 \%$ & $-0.77 \%$ \\
Avg. Allocation to UST1-5y & $25 \%$ & $14 \%$ & $89 \%$ & $35 \%$ \\
Avg. Allocation to UST5-10y & $25 \%$ & $5 \%$ & $1 \%$ & $17 \%$ \\
Avg. Allocation to AA1-5y & $25 \%$ & $74 \%$ & $10 \%$ & $32 \%$ \\
Avg. Allocation to AA5-10y & $25 \%$ & $7 \%$ & $0 \%$ & $16 \%$ \\
\hline
\end{tabular}

Table 3. Volatilities of the Combinations between Bond Indexes and Guarantee Portfolios

Volatilities of the combined returns between a bond index and a guarantee portfolio are estimated with monthly data starting from January 1992 to December 2012. The return of the high-grade short-term guarantee portfolio is the return of the HG 1-5Y index minus the return of the UST 1-5Y index. The return of the high-yield short-term guarantee portfolio is the return of the HY $1-5 \mathrm{Y}$ index minus the return of the UST 1-5Y index. The return of the high-grade long-term guarantee portfolio is the return of the HG $1-10$ Y index minus the return of the UST 1-10Y index. The leverage of guarantee portfolio is denoted as $L$. $L$ is either $100 \%$ or $200 \%$.

\begin{tabular}{|c|c|c|}
\hline Combinations & $\begin{array}{c}\text { Volatility } \\
(L=100 \%)\end{array}$ & $\begin{array}{l}\text { Volatility } \\
(L=200 \%)\end{array}$ \\
\hline UST1-5Y + high-grade short-term Guarantee portfolio $* L$ & $2.85 \%$ & $4.51 \%$ \\
\hline UST5-10Y + high-grade short-term Guarantee portfolio ${ }^{*} L$ & $5.85 \%$ & $6.74 \%$ \\
\hline AA1-5Y + high-grade short-term Guarantee portfolio $* L$ & $3.34 \%$ & $5.19 \%$ \\
\hline AA5-10Y + high-grade short-term Guarantee portfolio $* L$ & $6.15 \%$ & $7.61 \%$ \\
\hline UST1-5Y + high-yield short-term Guarantee portfolio $* L$ & $6.52 \%$ & $13.65 \%$ \\
\hline UST5-10Y + high-yield short-term Guarantee portfolio ${ }^{*} L$ & $7.09 \%$ & $13.22 \%$ \\
\hline AA1-5Y + high-yield short-term Guarantee portfolio $* L$ & $7.16 \%$ & $14.29 \%$ \\
\hline AA5-10Y + high-yield short-term Guarantee portfolio $* L$ & $8.49 \%$ & $14.95 \%$ \\
\hline UST1-5Y + high-grade long-term Guarantee portfolio $* L$ & $3.25 \%$ & $5.99 \%$ \\
\hline UST5-10Y + high-grade long-term Guarantee portfolio $* L$ & $5.64 \%$ & $7.16 \%$ \\
\hline AA1-5Y + high-grade long-term Guarantee portfolio ${ }^{*} L$ & $3.88 \%$ & $6.74 \%$ \\
\hline AA5-10Y + high-grade long-term Guarantee portfolio $* L$ & $6.36 \%$ & $8.59 \%$ \\
\hline
\end{tabular}


In terms of volatility of annual performance, the minimum variance model is the lowest, the equal risk model is next, and the equal weight is the highest (Table 3). This is a natural result by the construction of the portfolios. In terms of risk return ratio, the equal risk model performs second, next to mean variance optimization model. The equity risk model allocates relatively large weight to the AA 1-5Y index although not as much as the mean variance optimization model. The minimum variance model produces extreme allocations corresponding to prior literature. Due to the high correlation among the bond indices, volatile bond indexes receive less allocation.

Table 4 shows out-of-sample performance of the four asset allocation methods. The sizes of the high-yield short-term guarantee portfolio and the investment portfolio are the same (100\% leverage). Table 4 is about the highyield guarantee portfolio, while Table 2 is about the high-grade guarantee portfolio. Similar to the previous results, the mean variance optimization model performs best in terms of risk return ratio. The minimum variance and equal risk models perform better than the equal weight model in terms of the risk return ratio. The minimum variance model perform slightly better than the equal risk model.

The allocation to US treasuries under the mean variance optimization model is $49 \%$ in Table 4 , higher than $19 \%$ in Table 2. The allocation to short-term bonds is $55 \%$ in Table 4 , lower than $88 \%$ in Table 2 . This result suggests that the increased risk in high-yield guarantee portfolio is effectively hedged by long-term US treasuries; the allocation to US treasuries increases for hedging when the guarantee portfolio becomes riskier. Using the equal risk model increases the allocation to the long-term bonds too (24\% in Table 4 vs. $17 \%$ in Table 2 ) because the longterm bonds are more negatively correlated with high-yield short-term guarantee portfolio than short-term bonds are.

Table 4. Out of Sample Performance: $100 \%$ Leverage on the High-yield Short-term Guarantee Portfolio

The out of sample performances are the annual performances from 1995 to 2013 of four asset allocation models. The annual return is the sum of the annual investment portfolio return and the annual guarantee portfolio return projected with the annual default rate and the average high-yield short-term credit spread from past five years. The parameters for models are estimated with previous three-year monthly data ending December just before a target year. Leverage is $100 \%$.

\begin{tabular}{lccrr}
\hline & Equal Weight & $\begin{array}{c}\text { Mean-Variance } \\
\text { Optimization }\end{array}$ & $\begin{array}{c}\text { Minimum } \\
\text { Variance }\end{array}$ & Equal Risk \\
\hline Average Return & $6.31 \%$ & $6.91 \%$ & $5.81 \%$ & $6.19 \%$ \\
S.D. of Returns & $4.24 \%$ & $3.71 \%$ & $3.74 \%$ & $4.05 \%$ \\
Risk Return Ratio & 1.49 & 1.86 & 1.55 & 1.53 \\
Worst Year's Return & $-1.83 \%$ & $-1.04 \%$ & $-2.68 \%$ & $-1.38 \%$ \\
Avg. Allocation to UST1-5y & $25 \%$ & $19 \%$ & $77 \%$ & $29 \%$ \\
Avg. Allocation to UST5-10y & $25 \%$ & $30 \%$ & $23 \%$ & $24 \%$ \\
Avg. Allocation to AA1-5y & $25 \%$ & $36 \%$ & $0 \%$ & $27 \%$ \\
Avg. Allocation to AA5-10y & $25 \%$ & $15 \%$ & $0 \%$ & $20 \%$ \\
\hline
\end{tabular}

Intuitive explanations on the result are as follow. First, the guarantee portfolio bearing high credit risk generates high guarantee fees. Then the yield generated from investment portfolio becomes less important. The relative importance of the yield increases when the guarantee portfolio bears low credit risk (guarantee fees are low). Second, the guarantee portfolio bearing high credit risk can increase default loss. Since US treasuries are the most liquid bonds, they can be easily liquidated to compensate default losses whenever required. Third, under recession, defaults occur more often; but long-term US treasuries perform better than the others. Hence, increased allocation to UST 5-10Y index can mitigate the risk of a credit guarantor under recession. 
Table 5. Out of Sample Performance: $100 \%$ Leverage on the High-grade Long-term Guarantee Portfolio The out of sample performances are the annual performances from 1995 to 2013 of four asset allocation models. Annual return is the sum of annual investment portfolio return and annual guarantee portfolio return projected with annual default rate and the average high-grade long-term credit spread from past five years. The parameters for models are estimated with previous threeyear monthly data ending December just before a target year. Leverage is $100 \%$.

\begin{tabular}{|c|c|c|c|c|}
\hline & Equal Weight & $\begin{array}{c}\text { Mean-Variance } \\
\text { Optimization }\end{array}$ & $\begin{array}{c}\text { Minimum } \\
\text { Variance }\end{array}$ & Equal Risk \\
\hline Average Return & $5.58 \%$ & $5.54 \%$ & $4.53 \%$ & $5.29 \%$ \\
\hline S.D. of Returns & $4.32 \%$ & $3.83 \%$ & $3.50 \%$ & $3.93 \%$ \\
\hline Risk Compensation Ratio & 1.29 & 1.45 & 1.29 & 1.35 \\
\hline Worst Year's Return & $-1.68 \%$ & $-3.03 \%$ & $-1.12 \%$ & $-1.46 \%$ \\
\hline Avg. Allocation to UST1-5y & $25 \%$ & $21 \%$ & $91 \%$ & $34 \%$ \\
\hline Avg. Allocation to UST5-10y & $25 \%$ & $11 \%$ & $4 \%$ & $19 \%$ \\
\hline Avg. Allocation to AA1-5y & $25 \%$ & $57 \%$ & $5 \%$ & $31 \%$ \\
\hline Avg. Allocation to AA5-10y & $25 \%$ & $11 \%$ & $0 \%$ & $16 \%$ \\
\hline
\end{tabular}

Table 5 shows out of sample performance when the sizes of the high-grade long-term guarantee portfolio and investment portfolio are the same (100\% leverage). In Table 5, the maturities of the guarantee are up to 10 years whereas they are five years in Table 2 . The performance of mean variance optimization model is still the best. The allocation to US treasuries is $33 \%$, higher than $19 \%$ in Table 2 . The allocation to short-term bonds is $78 \%$, lower than $88 \%$ in Table 2 . These allocations are closer to those of Table 4 than to those of Table 2 . This means that the long-term US treasuries are less required for the high-grade long-term guarantee portfolio than for the high-yield short-term guarantee portfolio; optimal maturity allocation of investment portfolio does not always follow the maturity characteristic of guarantee portfolio.

Table 6. Out of Sample Performance: $200 \%$ Leverage on High-grade Short-term Guarantee Portfolio The out of sample performances are the annual performances from 1995 to 2013 of four asset allocation models. Annual return is the sum of the annual investment portfolio return and annual guarantee portfolio return projected with annual default rate and the average high-grade short-term credit spread from past five years. The parameters for models are estimated with previous threeyear monthly data ending December just before a target year. Leverage is $200 \%$.

\begin{tabular}{lccrr} 
& Equal Weight & $\begin{array}{c}\text { Mean-Variance } \\
\text { Optimization }\end{array}$ & $\begin{array}{c}\text { Minimum } \\
\text { Variance }\end{array}$ & Equal Risk \\
\hline Average Return & $5.41 \%$ & $5.47 \%$ & $4.39 \%$ & $5.17 \%$ \\
S.D. of Returns & $4.29 \%$ & $3.63 \%$ & $3.40 \%$ & $3.94 \%$ \\
Risk Compensation Ratio & 1.26 & 1.50 & 1.29 & 1.31 \\
Worst Year's Return & $-2.25 \%$ & $-0.75 \%$ & $-2.65 \%$ & $-1.50 \%$ \\
Avg. Allocation to UST1-5y & $25 \%$ & $15 \%$ & $92 \%$ & $33 \%$ \\
Avg. Allocation to UST5-10y & $25 \%$ & $15 \%$ & $3 \%$ & $19 \%$ \\
Avg. Allocation to AA1-5y & $25 \%$ & $62 \%$ & $5 \%$ & $31 \%$ \\
Avg. Allocation to AA5-10y & $25 \%$ & $8 \%$ & $0 \%$ & $17 \%$ \\
\hline
\end{tabular}

Table 6 shows the out of sample performance results where the size of the high-grade short-term guarantee portfolio is twice the size of the investment portfolio. Thus, Table 6 reports the result of $200 \%$ leverage, while Table 2 reports that of $100 \%$. Similar to Table 2, the mean variance optimization model performs the best in terms of risk return ratio with the equal risk model the second best. Under mean variance optimization, the allocation to US treasuries is $30 \%$, higher than $19 \%$ in Table 2 . The allocation to the long-term bonds is $23 \%$, increased from $12 \%$ in Table 2. The larger the leverage, the more the risk becomes. This requires more treasuries and long-term bond as shown in Table 6. The allocations in equal risk model do not change much despite the increase in leverage from Table 2.

To verify our intuition so far, we compare $200 \%$ leverage case of the high-grade guarantee portfolio with $100 \%$ leverage case with the high-yield one. The portfolio weights are more tilted in the latter despite its lower leverage; the latter requires more allocations to the US treasuries than the former does. This happens because the estimated volatility of the high-yield short-term portfolio is more than twice of that of the high-grade short-term portfolio (see panel A of Table 1). 
Table 7. Out of Sample Performance: 200\% Leverage on the Speculative Grade Short-term Guarantee Portfolio The out of sample performances are the annual performances from 1995 to 2013 of four asset allocation models. The annual return is the sum of the annual investment portfolio return and annual guarantee portfolio return projected with the annual default rate and the average speculative grade short-term credit spread from past five years. The parameters for models are estimated with previous three-year monthly data ending December just before a target year. Leverage is $200 \%$.

\begin{tabular}{|c|c|c|c|c|}
\hline & Equal Weight & $\begin{array}{c}\text { Mean-Variance } \\
\text { Optimization }\end{array}$ & $\begin{array}{c}\text { Minimum } \\
\text { Variance } \\
\end{array}$ & Equal Risk \\
\hline Average Return & $6.83 \%$ & $7.41 \%$ & $7.02 \%$ & $6.80 \%$ \\
\hline S.D. of Returns & $4.82 \%$ & $4.72 \%$ & $6.03 \%$ & $4.82 \%$ \\
\hline Risk Compensation Ratio & 1.42 & 1.57 & 1.16 & 1.41 \\
\hline Worst Year's Return & $-3.72 \%$ & $-3.33 \%$ & $-7.35 \%$ & $-3.91 \%$ \\
\hline Avg. Allocation to UST1-5y & $25 \%$ & $10 \%$ & $40 \%$ & $26 \%$ \\
\hline Avg. Allocation to UST5-10y & $25 \%$ & $40 \%$ & $60 \%$ & $26 \%$ \\
\hline Avg. Allocation to AA1-5y & $25 \%$ & $27 \%$ & $0 \%$ & $25 \%$ \\
\hline Avg. Allocation to AA5-10y & $25 \%$ & $24 \%$ & $0 \%$ & $23 \%$ \\
\hline
\end{tabular}

Table 8: Out of Sample Performance: 200\% Leverage on the High-grade Long-term Guarantee Portfolio The out of sample performances are the annual performances from 1995 to 2013 of the four asset allocation models. Annual return is the sum of the annual investment portfolio return and the annual guarantee portfolio return projected with the annual default rate and the average high-grade long-term credit spread over the past five years. The parameters for models are estimated with previous three-year monthly data ending December just before a target year. Leverage is $200 \%$.

\begin{tabular}{lccrr}
\hline & Equal Weight & $\begin{array}{c}\text { Mean-Variance } \\
\text { Optimization }\end{array}$ & $\begin{array}{c}\text { Minimum } \\
\text { Variance }\end{array}$ & Equal Risk \\
\hline Average Return & $5.36 \%$ & $5.53 \%$ & $4.50 \%$ & $5.17 \%$ \\
S.D. of Returns & $4.34 \%$ & $3.87 \%$ & $3.77 \%$ & $4.08 \%$ \\
Risk Compensation Ratio & 1.23 & 1.43 & 1.19 & 1.27 \\
Worst Year's Return & $-2.17 \%$ & $-3.70 \%$ & $-2.96 \%$ & $-1.51 \%$ \\
Avg. Allocation to UST1-5y & $25 \%$ & $25 \%$ & $87 \%$ & $31 \%$ \\
Avg. Allocation to UST5-10y & $25 \%$ & $20 \%$ & $13 \%$ & $22 \%$ \\
Avg. Allocation to AA1-5y & $25 \%$ & $41 \%$ & $0 \%$ & $29 \%$ \\
Avg. Allocation to AA5-10y & $25 \%$ & $14 \%$ & $0 \%$ & $18 \%$ \\
\hline
\end{tabular}

Table 7 shows the out of sample performance when the size of the high-yield short-term guarantee portfolio is twice the size of the investment portfolio (200\% leverage). The mean variance optimization model performs best in terms of risk return ratio. The allocation to US treasuries is almost unchanged. Instead, the average maturity of the optimal allocation increases.

The minimum variance model produces maximum volatility, not minimum, in the out of sample. Table 3 suggests that the UST 5-10Y index can reduce volatility when the leverage of the high-yield short-term guarantee portfolio is $200 \%$. As a result, the minimum variance model allocates large weight to the UST 5-10Y. However, when the out of sample performances are calculated, the return of the guarantee portfolio is driven by the actual default rate and the average credit spread. Panel B of Table 1 shows that the volatility of UST 5-10Y index is $6.97 \%$, the highest among four bond indices, and that of high-yield short-term guarantee portfolio is only $1.80 \%$. Even if leverage is $200 \%$, the volatility from the guarantee portfolio is much smaller than that from the UST 5-10Y index. As a result, the minimum variance model with a large allocation to the UST 5-10 index produces the largest volatility. The equal risk model and the equal weight model produce similar results. The weight generated from equal risk model is evenly distributed since the risk of each asset is dominated by high-yield guarantee portfolio with $200 \%$ leverage. Hence, the risk from each asset is almost identical.

Table 8 shows the out of sample performance when the size of the high-grade long-term guarantee portfolio is twice of the size of the investment portfolio (200\% leverage). The mean variance optimization model performs best in terms of risk return ratio. The allocation to US treasuries is $45 \%$, increased from $32 \%$ in Table 5 with $100 \%$ leverage. The allocation to long-term bonds is $34 \%$, increased from $22 \%$ in Table 5 . The change in allocation after leverage hike is in line with previous results. The equal risk model performs second best. Although the allocation to US treasuries is almost unchanged, the allocation to long-term bonds increases by $5 \%$ from Table 5 . Minimum variance model performs the worst. 


\section{SUMMARY AND CONCLUSION}

Our analysis produces many interesting results. First, the mean variance optimization model is the best among four models in terms of risk return ratio. The mean variance optimization model always beats the other models regardless of characteristics of guarantee portfolio or leverage. Contrary to previous research criticizing mean variance optimization model, this study shows its superiority over other models which do not require expected return estimation. We use yield instead of historical average for expected returns. Note that prior research uses the historical average returns as expected return estimates when mean variance optimization is employed. Since we take advantage of the latest yield as our expected return estimate, our empirical test indirectly supports mean variance optimization if expected returns are reasonably set.

Second, the riskier the guarantee portfolio of a credit guarantor, the more US treasuries and long-term bonds are required. This pattern arises not only in mean variance optimization model, but also in equal risk model. Our mean variance optimization and equal risk models are the best and the second best in terms of risk return ratio. This result is also intuitive because US treasuries and long-term bonds perform well under economic distress where there are many realized defaults. Therefore, the more the increase in the guarantee portfolio, the larger the diversification benefits from US treasuries and long-term bonds.

Prior literature little investigates the asset allocation problem of credit guarantors. Credit guarantors generally invest in fixed income securities. They are mostly government related entities. This study focuses on the unique feature of creditor guarantor portfolios. Thus, it contributes to academic researchers and practical managers interested in the capital management of credit guarantors.

Although we try to set a realistic framework, there are still limitations; one of many others would be rebalancing schedule. Since most credit guarantors hold fixed income securities up to the maturities for their management reasons, it seems difficult to fully implement the rebalancing strategy suggested in this paper. Future research can study this issue in detail.

\section{AUTHOR INFORMATION}

Dr. Dong-Woo Rhee is currently working as a Treasury Specialist at CGIF (Credit Guarantee and Investment Facility) which is a trust fund of ADB (Asian Development Bank). Prior to CGIF, he worked for Samsung Asset Management as a fixed income portfolio manager. He holds bachelor's degree in business administration from Sogang University and both master and doctorial degrees in business engineering from KAIST (Korea Advanced Institute of Science and Technology).

Dr. Hyoung-Goo Kang is an assistant professor of the department of finance at Hanyang University Business School. He received his PhD and MA from the Fuqua School of Business at Duke University, his MA from the economics department at University of Virginia and his BA from the economics department at Seoul National University. He has worked at Lehman Brothers Quantitative Research, Samsung Asset Management, International Monetary Fund, Accenture Management Consulting and Republic of Korea Air Force. He was also a non-resident research fellow of the Edmond J. Safra Center for Ethics at Harvard University. E-mail: hyoungkang@hanyang.ac.kr (Corresponding author)

Dr. Soo-Hyun Kim is currently an Assistant Professor of Finance at School of business administration of Soongsil University. Prior to Soongsil University, he worked for Samsung Asset Management as a quantitative strategist. He holds B.A. in economics from Seoul National University, and M.A. both in international economics and statistics. $\mathrm{He}$ completed his Ph.D. degree in industrial engineering (applied statistics for finance) at Georgia Institute of Technology. 


\section{REFERENCES}

Allen G.C. (2010), The Risk Parity Approach to Asset Allocation, Callan Investments Institute, Callan Associates, February 2010.

Behr P., Guttler A. and Miebs F. (2008), Is Minimum-Variance Investing Really Worth the While? An Analysis with Robust Performance Inference, Working Paper, September.

Benartzi S. and Thaler R.H. (2001), Naive diversification strategies in defined contribution saving plans, American Economic Review, 91(1), pp. 79-98.

Booth D. and Fama E. (1992), Diversification and asset contributions, Financial Analyst Journal, 48(3), pp. 26-32.

Chaves D., Hsu J., Li F. and Shakernia O. (2010), Risk Parity Portfolio vs. Other Asset Allocation Heuristic Portfolios, SSRN.

Choueifaty Y. and Coignard Y. (2008), Towards maximum diversification, Journal of Portfolio Management, 34(4), pp. 40-51.

Clarke R., de Silva H. and Thorley S. (2006), Minimum-variance portfolios in the U.S. equity market, Journal of Portfolio Management, 33(1), pp. 10-24.

DeMiguel V., Garlappi L. and Uppal R. (2009), Optimal Versus Naive Diversification: How Inefficient is the 1/N Portfolio Strategy?, Review of Financial Studies, 22, pp. 1915-1953.

Duffee G. (1998), The Relationship between Treasury Yields and Corporate Bond Yield Spreads, The Journal of Finance, 53, pp. 2225-2241.

Düllmann, K., Uhrig-Homburg, M., \& Windfuhr, M. (2000). Risk structure of interest rates: an empirical analysis for Deutschemark-denominated bonds. European Financial Management, 6(3), 367-388.

Fernholtz R., Garvy R. and Hannon J. (1998), Diversity-Weighted indexing, Journal of Portfolio Management, 4(2), pp. 74-82.

Foresti S.J. and Rush M.E. (2010), Risk-Focused Diversification: Utilizing Leverage within Asset Allocation, Wilshire Consulting Paper, February 11.

Inker B. (2010), The Hidden Risks of Risk Parity Portfolios, GMO White Paper, March.

Jorion P. (1986), Bayes-Stein estimation for portfolio analysis, Journal of Financial and Quantitative Analysis, 21, pp. 293-305.

Levell C.A. (2010), Risk Parity: In the Spotlight after 50 Years, NEPC, March.

Maillard S., Roncalli T. and Teiletche J. (2010), The Properties of Equally Weighted Risk Contribution Portfolios, Journal of Portfolio Management, 36(4), pp. 60-70.

Markowitz H.M. (1952), Portfolio selection, Journal of Finance, 7, pp. 77-91.

Markowitz H.M. (1956), The optimization of a quadratic function subject to linear constraints, Naval research logistics Quarterly, 3, pp. 111-133.

Martellini L. (2008), Toward the design of better equity benchmarks, Journal of Portfolio Management, 34(4), pp. 18.

Merton R.C. (1980), On estimating the expected return on the market: An exploratory investigation, Journal of Financial Economics, 8, pp. 323-361.

Michaud R. (1989), The Markowitz optimization enigma: Is optimized optimal?, Financial Analysts Journal, 45, pp. 31-42.

Neurich Q. (2008), Alternative indexing with the MSCI World Index, SSRN.

Qian E. (2005), Risk parity portfolios: E-cient portfolios through true diversification, Panagora Asset Management, September.

Qian E. (2006), On the financial interpretation of risk contributions: Risk budgets do add up, Journal of Investment Management, Fourth Quarter.

Roncalli T. (2014), Introducing Expected Returns into Risk Parity Portfolios: A New Framework for Tactical and Strategic Asset Allocation, SSRN.

Scherer B. (2007), Can robust portfolio optimization help to build better portfolios?, Journal of Asset Management, 7(6), pp. 374-387.

Schweizer M. (1992), Mean-Variance Hedging for General Claims, The Annals of Applied Probability, 2(1), pp. 171-179.

Tütüncü R.H and Koenig M. (2004), Robust asset allocation, Annals of Operations Research, 132, pp. 132-157.

Walder R. (2002), Dynamic Allocation of Treasury and Corporate Bond Portfolios, SSRN.

Windcliff H. and Boyle P. (2004), The 1/n pension plan puzzle, North American Actuarial Journal, 8, pp. 32-45. 


\section{NOTES}

